\title{
Papers
}

\section{Atypical antipsychotic drugs in the treatment of behavioural and psychological symptoms of dementia: systematic review}

Philip E Lee, Sudeep S Gill, Morris Freedman, Susan E Bronskill, Michael P Hillmer, Paula A Rochon

\begin{abstract}
Objective To review the role of oral atypical antipsychotic drugs in the management of the behavioural and psychological symptoms of dementia (BPSD).

Data sources Medline, Embase, and the Cochrane Library.

Reference lists were reviewed and experts were contacted to identify additional trials.

Study selection Double blind randomised controlled trials that evaluated the four oral atypical antipsychotic therapies for BPSD.

Review methods Two reviewers assessed trial validity independently.

Data extraction Demographics of patients, study duration, dose of antipsychotic, primary end points, adverse events.

Results 77 abstracts were reviewed. Five randomised trials (1570 patients) evaluating risperidone and olanzapine were identified. The quality of trials was generally good. Most participants were in an institution $(>96 \%)$, elderly (weighted mean 82.3 years), and had Alzheimer's disease (76.3\%). Trials lasted 6-12 weeks. Treatment with atypical antipsychotic drugs was superior to placebo for the primary end point in three of the five trials. Two trials comparing risperidone with haloperidol did not find any differences in the primary measures of efficacy. Adverse events were common and included extrapyramidal symptoms, somnolence, and abnormal gait.
\end{abstract}

Conclusions Although atypical antipsychotic drugs are being used with increasing frequency, few randomised trials have evaluated their use for BPSD. Limited evidence supports the perception of improved efficacy and adverse event profiles compared with typical antipsychotic drugs.

\section{Introduction}

The term "behavioural and psychological symptoms of dementia" (BPSD) has been proposed to describe the spectrum of non-cognitive manifestations of dementia that include verbal and physical aggression, agitation, psychotic symptoms (hallucinations and delusions), sleep disturbances, and wandering. ${ }^{1}$ BPSD can decrease quality of life for patients and caregivers and increase the likelihood of admission to an institution. ${ }^{2}$

Management of BPSD has not been standardised and currently entails various non-pharmacological and pharmacological approaches. For many years, typical antipsychotic (neuroleptic) drugs were the most common treatment. Although there has been extensive experience with their use, typical antipsychotics are only modestly effective and have potentially serious adverse effects that limit their usefulness in older adults. ${ }^{3}$
In the United States, concerns about overuse of antipsychotics led to the introduction of legislation (Omnibus Reconciliation Act 1987) that attempted to restrict prescribing of antipsychotics to residents of nursing homes. ${ }^{4}$ Before the introduction of the act, up to $55 \%$ of nursing home residents were treated with antipsychotic drugs. ${ }^{5}$ This legislation had a considerable impact on the use of such drugs in nursing homes. ${ }^{46}$ Several trials have shown that antipsychotics can often be safely discontinued in people in long term care. ${ }^{78}$ The experience in the United States has led some authors to examine how similar policies could be adopted in the United Kingdom. ${ }^{9}$

More recently, atypical antipsychotics have become available. These drugs have been widely adopted to treat psychotic disorders because they are perceived to have superior efficacy and safety compared with typical agents. Like typical antipsychotics, atypical antipsychotics block $\mathrm{D}_{2}$ receptors but they also antagonise serotonergic receptors such as $5-\mathrm{HT}_{2}$. Depending on the specific drug, there may be effects on muscarinic, $\alpha$ adrenergic, or histaminic receptors. The results of blocking these receptors include anticholinergic effects, orthostatic hypotension, and sedation.

Compared with typical antipsychotic agents, atypical antipsychotics are thought to be less likely to cause extrapyramidal symptoms such as parkinsonism and tardive dyskinesia. ${ }^{10-12}$ Data supporting the efficacy and safety of atypical antipsychotics need to be examined, especially in light of their high costs and newly identified adverse events. These drugs may be associated with serious adverse events, especially among patients with risk factors such as metabolic disease. ${ }^{13}$

While the use of atypical antipsychotic drugs has been well studied in younger adults with psychotic symptoms, less information is available regarding their use in older adults. In practice, however, atypical antipsychotics are increasingly used to treat older patients with BPSD, and there have been striking increases in expenditures for antipsychotic drugs with their introduction. A Canadian study using data from 1998-2000 found that $24 \%$ of nursing home residents with no previous exposure to antipsychotics were newly started on an antipsychotic drug during their first year after admission, and atypical antipsychotics accounted for $40 \%$ of these prescriptions. ${ }^{14}$ Despite their frequent use in Canada, only risperidone has been indicated for the treatment of behavioural disturbance in patients with severe dementia. ${ }^{15}$ In the United Kingdom and United States, the treatment of BPSD is not listed as an indication for the use of any atypical antipsychotic drug. ${ }^{16} 17$

To assess the benefits and risks of atypical antipsychotic drugs for BPSD, we performed a systematic review of the randomised trials in this field. 


\begin{tabular}{|c|c|c|c|c|c|}
\hline & Katz, $1999^{25}$ & De Deyn, $1999^{24}$ & Chan, $2001^{23}$ & Brodaty, $2003^{22}$ & Street, $2000^{26}$ \\
\hline Interventions & Risperidone $v$ placebo & $\begin{array}{l}\text { Risperidone } v \text { haloperidol } v \\
\text { placebo }\end{array}$ & Risperidone $v$ haloperidol & Risperidone $v$ placebo & Olanzapine $v$ placebo \\
\hline No of patients & $\begin{array}{c}625 \text { (462 risperidone, } 163 \\
\text { placebo) }\end{array}$ & $\begin{array}{l}344 \text { (115 risperidone, } 115 \\
\text { haloperidol, } 114 \text { placebo) }\end{array}$ & $\begin{array}{c}58 \text { (29 risperidone, } 29 \\
\text { haloperidol) }\end{array}$ & $\begin{array}{c}337 \text { (167 risperidone, } 170 \\
\text { placebo) }\end{array}$ & $\begin{array}{c}206 \text { (159 olanzapine, } 47 \\
\text { placebo) }\end{array}$ \\
\hline Drug dose (per day) & Fixed: $0.5,1$, or $2 \mathrm{mg}$ & $\begin{array}{c}\text { Flexible: mean } 1.1 \mathrm{mg} \\
\text { risperidone, } 1.2 \mathrm{mg} \\
\text { haloperidol }\end{array}$ & $\begin{array}{l}\text { Flexible: mean } 0.85 \mathrm{mg} \\
\text { risperidone, } 0.9 \mathrm{mg} \\
\text { haloperidol }\end{array}$ & Flexible: mean 0.95 mg & Fixed: 5,10 , or $15 \mathrm{mg}$ \\
\hline Duration (weeks) & 12 & 12 & 12 & 12 & 6 \\
\hline Mean age (years) & 82.6 & 81.3 & 80.5 & 83.0 & 82.8 \\
\hline Diagnosis & $\begin{array}{c}73 \% \mathrm{AD}, 15 \% \mathrm{VaD}, 11 \% \\
\text { mixed }\end{array}$ & $67 \% \mathrm{AD}, 26 \% \mathrm{VaD}, 7 \%$ mixed & $79 \% \mathrm{AD}, 21 \% \mathrm{VaD}$ & $\begin{array}{c}58 \% \mathrm{AD}, 29 \% \mathrm{VaD}, 13 \% \\
\text { mixed }\end{array}$ & $100 \% \mathrm{AD}$ \\
\hline Mean MMSE (out of 30$)^{27}$ & 6.6 & 8.4 & 8.0 & 5.5 & 6.7 \\
\hline \multicolumn{6}{|l|}{ Assessment of quality: } \\
\hline Randomisation ${ }^{\star}$ & 1 & 2 & 1 & 1 & 2 \\
\hline Blinding $\dagger$ & 2 & 2 & 1 & 2 & 2 \\
\hline Withdrawals/dropoutsł & 1 & 1 & 1 & 1 & 1 \\
\hline Jadad quality score§ & 4 & 5 & 3 & 4 & 5 \\
\hline Concealmentף & 0 & 1 & 0 & 0 & 1 \\
\hline Follow up up $^{\star \star}$ & 2 & 2 & 2 & 2 & 2 \\
\hline
\end{tabular}

$\mathrm{AD}=$ Alzheimer's disease; MMSE=Folstein mini mental state examination; VaD=vascular dementia.

${ }^{*} 0=$ not randomised or pseudo-randomised; 1=randomised, method not described; $2=$ randomised, appropriate method reported.

†0=no blinding or inappropriate method; $1=$ double blind, blinding not reported; $2=$ double blind, blinding appropriate.

$\ddagger 0=$ not described for each group; $1=$ described by group.

$\S$ Score out of 5, based on scores for randomisation, blinding, and withdrawals/dropouts; does not consider concealment of allocation or adequacy of follow up. ${ }^{17}$

१0=no concealment process described; $1=$ concealment process described.

${ }^{\star *} 0=$ no or inadequate reporting of follow up; $1=$ reported, data not analysed according to intention to treat; $2=$ reported, data analysed according to intention to treat.

\section{Methods}

\section{Search strategy}

We carried out electronic searches of Medline (1966-September 2003), Embase (1980-September 2003), and the Cochrane library (issue 1, 2003). We used MeSH headings: dementia, antipsychotic agents, atypical, risperidone or risperdal, olanzapine or zyprexa, quetiapine or seroquel, and clozapine or clozaril, and searched for Enzyme Commission numbers assigned to new substances identified by the Chemical Abstracts Service registry. We also manually searched reference lists and contacted clinical experts to identify additional trials.

\section{Selection of eligible trials}

We included all published double blind randomised controlled trials that evaluated the four oral atypical antipsychotic drugs used to treat BPSD available in Canada, the United States, and the United Kingdom (clozapine, risperidone, olanzapine, and quetiapine). Drugs such as amisulpride, zotepine, and sertindole are also available in the United Kingdom, ${ }^{16}$ and aripiprazole and ziprasidone are available in the United States. ${ }^{18}$ Our search found no randomised trials evaluating these medications. Two geriatric medicine specialists (PEL and SSG) reviewed each abstract to select papers meeting inclusion criteria.

The two reviewers independently appraised each trial using a standardised form to record data relating to demographics of patients, study duration, drug dose, and primary end points. We extracted data on the most common and serious reported adverse events. The two reviewers also independently scored the methodological quality of the trials. ${ }^{19}{ }^{20}$

\section{Results}

From the 77 abstracts reviewed, we identified five randomised trials (1570 patients). ${ }^{22-26}$ Of the remaining abstracts, 66 described articles that did not meet our inclusion criteria (for example, letters, review articles, observational studies), one study was an open label extension of a previously published trial, and four studies involved post hoc analyses of trial data. We also excluded a trial that evaluated intramuscular olanzapine ${ }^{21}$ because of the route of administration and short length of follow up (24 hours).

Four trials evaluated risperidone, and one evaluated olanzapine. All trials were sponsored by the pharmaceutical industry. Table 1 details the assessments of trial quality. In general, trials were of good quality, but only two adequately reported efforts to maintain concealment of allocation. ${ }^{20}$ Table 1 also gives characteristics of the participants. Most participants were in an institution $(>96 \%)$. The Chan trial also enrolled some people who were living in the community. ${ }^{23}$ The weighted mean age of participants was 82.3 years, and most had severe dementia (mean score on mini-mental state examination ${ }^{27}$ was 6.8 out of $30)$.

Table 2 outlines the main efficacy results. Several factors made interpretation of the efficacy outcomes in the trials complex. Firstly, several different measurement scales were used to assess the benefits of atypical antipsychotics in managing BPSD. For example, the behavioural pathology in Alzheimer's disease rating scale (BEHAVE-AD) is a 25 item scale that measures behavioural symptoms in seven clusters (paranoid and delusional ideation; hallucinations; activity symptoms; aggressiveness; diurnal rhythm symptoms; affective symptoms; and anxieties and phobias) scored on 4 point scales of increasing severity. ${ }^{24}$ Other scales included the Cohen-Mansfield agitation inventory (CMAI), ${ }^{129}$ the neuropsychiatric inventory-nursing home version (NPI-NH) ${ }^{30}$ the brief psychiatric rating scale (BPRS), ${ }^{31}$ and the clinical global impressions (CGI) scale. ${ }^{32}{ }^{33} \mathrm{~A}$ second element of complexity arose from the fact that trials measured "clinical response" to treatment in different ways. For example, De Deyn et al measured both the proportion of participants achieving $>30 \%$ reduction in total BEHAVE-AD scores and the change in mean BEHAVE-AD scores from baseline. ${ }^{24}$ In contrast, Katz et al defined clinical response as $\geq 50 \%$ reduction in BEHAVE-AD scores. ${ }^{25}$ Thirdly, the trials often reported changes on both total scores and several subscale scores (for example, the aggressiveness subscale of BEHAVE-AD). Finally, the use of multiple comparisons can inflate the type I error rate. 
Table 2 Efficacy and safety results from included trials

\begin{tabular}{|c|c|c|c|c|c|c|c|c|c|c|}
\hline & \multicolumn{2}{|c|}{ Katz, $1999^{25}$} & \multicolumn{2}{|c|}{ De Deyn, $1999^{24}$} & \multicolumn{2}{|c|}{ Chan, $2001^{23}$} & \multicolumn{2}{|c|}{ Brodaty, $2003^{22}$} & \multicolumn{2}{|c|}{ Street, $2000^{26}$} \\
\hline & $\begin{array}{c}\text { Risperidone } \\
(1 \mathrm{mg} / \mathrm{day}) \\
(\mathrm{n}=148)\end{array}$ & $\begin{array}{l}\text { Placebo } \\
(n=163)\end{array}$ & $\begin{array}{c}\text { Risperidone } \\
(\mathrm{n}=115)\end{array}$ & $\begin{array}{r}\text { Placebo } \\
(n=114)\end{array}$ & $\begin{array}{l}\text { Risperidone } \\
(\mathrm{n}=29)\end{array}$ & $\begin{array}{l}\text { Haloperidol } \\
(\mathrm{n}=29)\end{array}$ & $\begin{array}{c}\text { Risperidone } \\
\text { ( } \mathrm{n}=167)\end{array}$ & $\begin{array}{l}\text { Placebo } \\
(\mathrm{n}=170)\end{array}$ & $\begin{array}{c}\text { Olanzapine (5 } \\
\mathrm{mg} / \mathrm{day}) \\
(\mathrm{n}=55)\end{array}$ & $\begin{array}{r}\text { Placebo } \\
(n=45)\end{array}$ \\
\hline \multicolumn{11}{|l|}{ Efficacy } \\
\hline Clinical end point & \multicolumn{2}{|c|}{$\begin{array}{c}\geq 50 \% \text { reduction in } \\
\text { BEHAVE-AD total score* }\end{array}$} & \multicolumn{2}{|c|}{$\begin{array}{c}\geq 30 \% \text { reduction in } \\
\text { BEHAVE-AD total score }\end{array}$} & \multicolumn{2}{|c|}{ Not specified } & \multicolumn{2}{|c|}{ CMAI total aggression score ${ }^{*}$} & \multicolumn{2}{|c|}{$\begin{array}{l}\geq 50 \% \text { reduction in NPI-NH } \\
\text { core total score }\end{array}$} \\
\hline $\begin{array}{l}\text { No (\%) who achieved } \\
\text { end point }\end{array}$ & $67(45)$ & $53(33+)$ & $62(54)$ & $54(47)$ & - & - & - & - & $36(66)$ & $16(36 \dagger)$ \\
\hline \multicolumn{11}{|l|}{ Change in total scores*: } \\
\hline BEHAVE-AD & -6.5 & $-4.2 \dagger$ & -8.6 & $-6.2 \dagger$ & - & - & -6.8 & $-2.3 \dagger$ & - & - \\
\hline CMAI & \multicolumn{2}{|c|}{ Raw data not provided $\dagger$} & -8.3 & $-4.9 \dagger$ & -8.1 & $-10.0 \ddagger$ & -7.5 & $-3.1 \dagger$ & - & - \\
\hline NPI-NH & - & - & - & - & - & - & - & - & -7.6 & $-3.7 \dagger$ \\
\hline \multicolumn{11}{|l|}{ No (\%) with effect } \\
\hline $\begin{array}{l}\text { Extrapyramidal } \\
\text { symptoms }\end{array}$ & $19(13)$ & $12(7 \ddagger)$ & $17(15)$ & $13(11 \ddagger)$ & \multicolumn{2}{|c|}{ Raw data not provided $\dagger$} & $39(23)$ & $27(16 \S)$ & \multicolumn{2}{|c|}{ Raw data not provided $\ddagger$} \\
\hline Any adverse event & $121(82)$ & $138(85)$ & $88(77)$ & $83(73)$ & \multicolumn{2}{|c|}{ NR } & 157 (94) & 157 (92) & \multicolumn{2}{|c|}{ NR } \\
\hline $\begin{array}{l}\text { Serious adverse } \\
\text { events }\end{array}$ & $24(16)$ & $21(13 \ddagger)$ & \multicolumn{2}{|c|}{ NR } & \multicolumn{2}{|c|}{ NR } & $28(17)$ & $15(9 \S)$ & \multicolumn{2}{|c|}{ NR } \\
\hline Withdrawals & 45 (30) & 44 (27§) & 47 (41) & 40 (35§) & $2(7)$ & 1 (3§) & 45 (27) & $56 \quad(33 \ddagger)$ & $11(20)$ & 11 (24‡) \\
\hline
\end{tabular}

BEHAVE-AD=behavioural pathology in Alzheimer's disease rating scale; CMAI=Cohen-Mansfield agitation inventory; NPI-NH=neuropsychiatric inventory-nursing home version; NR=not reported. *From baseline to end point.

$\dagger$ Significant improvement with risperidone or olanzapine $v$ control (haloperidol or placebo) $(\mathrm{P}<0.05$ considered to be significant).

‡No significant difference.

§Significance not reported.

Only three trials described statistical methods to compensate for making multiple comparisons. ${ }^{22} 2526$

\section{Efficacy of atypical antipsychotics $v$ placebo}

Katz et al compared three fixed doses of risperidone (0.5, 1 , and $2 \mathrm{mg}$ /day) with placebo. ${ }^{25}$ The BEHAVE-AD, CMAI, and CGI were used to measure efficacy. Patients who received 1 or 2 $\mathrm{mg}$ /day of risperidone showed significant improvements compared with the placebo group on several outcome measures.

De Deyn et al compared risperidone (mean dose at end point $1.1 \mathrm{mg} /$ day) with haloperidol ( $1.2 \mathrm{mg} /$ day $)$ and placebo. ${ }^{24}$ The primary outcome was the proportion of participants achieving $\geq 30 \%$ reduction from baseline to end point in BEHAVE-AD total scores. For this outcome, risperidone was not found to be superior to haloperidol or placebo (the proportions achieving this outcome in the risperidone, haloperidol, and placebo groups were $54 \%, 63 \%$, and $47 \%$, respectively). The authors, however, reported significant differences between risperidone and placebo on multiple secondary end points.

Brodaty et al compared flexible doses of risperidone (mean dose at end point $0.95 \mathrm{mg}$ /day) with placebo. ${ }^{22}$ The least squares mean (mean adjusted for the effect of baseline score and investigator) of the CMAI total aggression scores were significantly better with risperidone than with placebo. BEHAVE-AD total and subscale scores and CMAI scores were also better with risperidone.

The only published trial evaluating oral olanzapine was reported by Street et al. ${ }^{26}$ This trial randomised participants to placebo or one of three fixed doses of olanzapine $(5,10$, or 15 $\mathrm{mg} /$ day). The primary end point was the NPI-NH ${ }^{30}$ core total score, which was used to classify patients as responders $(\geq 50 \%$ reduction from baseline) or non-responders. On this measure, olanzapine 5 and $10 \mathrm{mg}$ /day were superior to placebo.

\section{Efficacy of atypical $v$ typical antipsychotic therapy}

Two trials compared risperidone with haloperidol. A post hoc analysis by De Deyn et al failed to show greater improvements with risperidone than with haloperidol on the BEHAVE-AD total scores but did show significant improvements with risperidone over haloperidol on aggressiveness subscales of BEHAVE-AD and CMAI. ${ }^{24}$ Chan et al randomly assigned 58 participants to flexible doses of $0.5-2 \mathrm{mg} /$ day of either risperidone or haloperidol. ${ }^{23}$ The primary outcome measure for this study was not specified. Both CMAI total scores and BEHAVE-AD subscores were reported, and no significant differences were found. However, the small sample size of this trial limits the conclusions that can be drawn from these results.

\section{Adverse events and withdrawals}

Investigators used various scales to specifically assess for extrapyramidal symptoms, a common adverse effect of antipsychotics. Symptom scales included the extrapyramidal symptom rating scale ${ }^{34}$ and the Simpson-Angus scale. ${ }^{35}$ Most symptoms examined were presumably due to parkinsonism because tardive dyskinesia would be unlikely to develop during these short trials (6-12 weeks). The trials of De Deyn et $\mathrm{al}^{24}$ and Brodaty et $\mathrm{al}^{22}$ (both of which used mean doses of about $1 \mathrm{mg} /$ day of risperidone) did not document significant differences in extrapyramidal symptoms associated with treatment than with placebo. Katz et al found a dose dependent increase in extrapyramidal symptoms with risperidone that was significant for participants receiving $2 \mathrm{mg} /$ day. ${ }^{25}$ Street et al reported no differences with olanzapine compared with placebo. $^{26}$ The two trials that compared risperidone and haloperidol both found that extrapyramidal symptoms were more common with haloperidol..$^{23} 25$

Other adverse events were often documented in the trials but were similar with treatment and placebo. De Deyn et al reported that somnolence was more common with risperidone than placebo. ${ }^{24}$ Street et al documented more somnolence and abnormal gait among participants receiving olanzapine than among those receiving placebo. ${ }^{26}$

Brodaty et al reported serious adverse events in $9 \%$ of participants receiving placebo and in $17 \%$ of those taking risperidone.22 In the risperidone group, six cerebrovascular adverse events were noted while none occurred in the placebo group.

Despite their short duration, most trials reported high withdrawal rates in the treatment and placebo groups. In two trials half of the withdrawals were due to adverse events. ${ }^{24}{ }^{25} \mathrm{Katz}$ et al found that withdrawals related to adverse events were dose 
dependent (12\% of placebo subjects $v 8 \%, 16 \%$, and $24 \%$ of participants received $0.5,1$, and $2 \mathrm{mg} /$ day of risperidone, respectively). ${ }^{25} \mathrm{~A}$ similar dose dependent withdrawal rate was found with olanzapine in the trial of Street et al. ${ }^{24}$ In the trial by Chan et al only three patients withdrew; one patient receiving risperidone withdrew because of a hip fracture..$^{23}$

\section{Discussion}

Our review identified only five trials evaluating use of oral atypical antipsychotic drugs to treat the behavioural and psychological symptoms of dementia (BPSD). No randomised controlled trials assessed clozapine or quetiapine for this indication. There have been no head to head trials comparing atypical antipsychotics. An independent review identified similar trials of atypical antipsychotic therapies and came to similar conclusions. ${ }^{36}$

The trials included in this review used the scores on the behavioural pathology in Alzheimer's disease (BEHAVE-AD), the Cohen-Mansfield agitation inventory (CMAI), and the neuropsychiatric inventory-nursing home version (NPI-NH) as their primary efficacy outcomes. These reliable and validated scales are commonly used to assess BPSD ${ }^{37}$ though because there is no consensus on which is best, different trials used different primary outcome measures. It is also not clear how much of a percentage change in each assessment tool represents a clinically significant response. Scales like the clinical global impressions scal ${ }^{32}{ }^{33}$ describe meaningful changes in overall clinical status.

Improvements in BPSD were commonly seen with atypical antipsychotics and with placebo. In the clinical course of BPSD symptoms often persist over periods as long as a year, ${ }^{38}$ and the improvements with placebo may result from nonpharmacological cointerventions received by all trial participants. Further research is needed to identify effective non-pharmacological interventions for BPSD. Regression to the mean may also contribute to the apparent placebo effect (that is, patients are enrolled into trials when BPSD symptoms are most severe).

The trials reviewed were short, lasting only 6-12 weeks. In clinical practice, however, patients with BPSD are sometimes maintained on antipsychotic drugs for months, and symptoms may persist for over a year. ${ }^{38}$ Street et al presented open label follow up results of their trial to six months. ${ }^{39}$ Other authors have claimed that atypical antipsychotics may be safe for long term treatment of BPSD. ${ }^{40}$ Ideally, a longer duration of follow up should be incorporated into future trials.

\section{Safety}

When treatment of BPSD is indicated, the choice of atypical antipsychotic drug is often made on the basis of how likely it is that patients will experience an adverse event. Without head to head trials, it is difficult to directly compare the efficacy or safety of atypical antipsychotic medications. Adverse events were common in treatment and placebo groups. This probably reflects the prevalence of comorbid disease in frail elderly patients. Common adverse events include antipsychotic-induced parkinsonism, somnolence, and abnormal gait. Adverse events seem to be dose related, supporting the practice of starting with a low dose and increasing slowly as the drug is tolerated.

There is increasing evidence that treatment with atypical antipsychotics may be associated with metabolic disturbances such as impaired glucose metabolism and hyperlipidaemia. ${ }^{13}$ Although many studies are observational, a recent randomised trial of typical and atypical antipsychotic therapy reported raised

\section{What is already known on this topic}

Antipsychotic drugs are commonly used to manage the behavioural and psychological symptoms of dementia (BPSD)

Newer "atypical" antipsychotic therapies are thought to have better efficacy and adverse event profiles than typical antipsychotic drugs

\section{What this study adds}

Only five published randomised trials have assessed the efficacy and safety of atypical antipsychotic drugs for BPSD

Evidence to support the perception of improved efficacy and adverse event rates is limited

Further evidence is required before such use of these drugs can be endorsed

glucose and cholesterol concentrations in patients with schizophrenia or schizoaffective disorder during 14 weeks' follow up. ${ }^{41}$ Even though the doses of antipsychotics used to treat BPSD are typically lower than those used in younger adult patients with psychotic symptoms, elderly patients may be more susceptible to adverse events because of changes in pharmacokinetics related to ageing and comorbid diseases. The trials we reviewed did not find evidence of such metabolic disturbances, but it is unlikely that these events would become apparent over only 6-12 weeks.

Brodaty et al reported an excess of cerebrovascular events and deaths among patients receiving risperidone. ${ }^{22}$ This study led Health Canada ${ }^{42}$ and the Food and Drug Administration ${ }^{43}$ to issue warnings that the use of risperidone in patients with dementia may be associated with an increased incidence of ischaemic stroke. All of the patients in that trial who had cerebrovascular events also had other risk factors for stroke, including atrial fibrillation, hypertension, and previous transient ischaemic attacks or strokes. The Committee on Safety of Medicines reviewed the data for both risperidone and olanzapine and concluded that the evidence showed increased risk of stroke. ${ }^{44}$ They suggested that risperidone and olanzapine should not be used for treating the behavioural and psychological symptoms of dementia.

\section{Future directions}

The National Institute of Mental Health is currently carrying out a 36 week study on Alzheimer's disease as part of the clinical antipsychotic trials of intervention effectiveness (CATIE). This study compares three atypical antipsychotic agents, a selective serotonin reuptake inhibitor, and placebo for treatment of BPSD. Results from this study are expected in $2006 .^{45}$

\section{Conclusions}

Although atypical antipsychotic drugs are being used with increasing frequency, only a few randomised trials have evaluated their use in BPSD. Additional evidence is required to support the perception of an improved efficacy and adverse event profile relative to typical antipsychotic agents. In light of concern regarding the potential adverse events associated with treatment with these drugs, further evidence is required before their use can be endorsed in the management of BPSD.

We thank Kathy Sykora, Walter Wodchis, and Kenneth Shulman for their suggestions regarding the manuscript revisions. We also acknowledge the 
expert assistance of Monica Lee and Susan Garfinkel in the production of this study.

Contributors: PEL, SSG, and PAR conceived the study, reviewed the literature, and wrote and revised the initial and subsequent drafts. PAR was also overseer of the research network. MF, SEB, and MPH contributed to data analysis and revisions of the manuscript. PEL and SSG are the guarantors. Funding: PEL's behavioural neurology fellowship was supported in part by Eli Lilly Canada. SSG was supported by a Canadian Institutes of Health Research (CIHR) Postdoctoral Fellowship. MF was supported by the Saul A Silverman Family Foundation (Toronto, Canada) as part of a CanadaInternational Scientific Exchange Program (CISEPO) project. PAR was supported by a CIHR Investigator Award. This work was supported by a CIHR operating grant (53124) and a CIHR Chronic Disease New Emerging Team (NET) programme grant (NET 54010). The NET programme receives joint sponsorship from the Canadian Diabetes Association, the Kidney Foundation of Canada, the Heart and Stroke Foundation of Canada, and the CIHR Institutes of Nutrition, Metabolism \& Diabetes, and Circulatory \& Respiratory Health. SEB was supported in part by New Investigator Award through the NET program.

Competing interests: MF has received honorariuns from Janssen-Ortho for participating in an advisory board meeting, consulting, and chairing an educational session, and has been supported by Janssen-Ortho to attend conferences. He has also received honorariums from Pfizer and Novartis and has been supported by Pfizer and Novartis to attend conferences. Ethical approval: Not required.

1 Cohen-Mansfield J, Billig N. Agitated behaviours in the elderly. I: a conceptual review. Am Geriatr Soc 1998;36:7-12

2 Cohen CA, Gold DP, Shulman KI, Wortley JT, McDonald G, Wargon M. Factors deter mining the decision to institutionalize dementing individuals: a prospective study. $\mathrm{Ger}$ ontologist 1993;33:714-20.

3 Schneider LS, Pollock VE, Lyness SA. A metaanalysis of controlled trials of neuroleptic treatment in dementia. J Am Geriatr Soc 1990;38:553-63.

4 Shorr RI, Fought RL, Ray WA. Changes in antipsychotic drug use in nursing homes during implementation of the OBRA-87 regulations. JAMA 1994;271:358-62.

5 Avorn J, Dreyer P, Connelly K, Soumerai SB. Use of psychoactive medication and the quality of care in rest homes. N Engl J Med 1989;320:227-32.

6 Semla TP, Palla K, Poddig B, Brauner DJ. Effect of the Omnibus Reconciliation Act 1987 on antipsychotic prescribing in nursing home residents. J Am Geriatr Soc 994:42:648-52

7 Avorn J, Soumerai SB, Everitt DE, Ross-Degnan D, Beers MH, Sherman D, et al. A randomized trial of a program to reduce the use of psychoactive drugs in nursing homes. N Engl J Med 1992;327:168-73.

8 Van Reekum R, Clarke D, Conn D, Herrmann N, Eryavec G, Cohen T, et al. A randomized, placebo-controlled trial of the discontinuation of long-term antipsychotics in dementia. Int Psychogeriatr 2002;14:197-210.

9 Hughes CM, Lapane KL, Mor V, Turrell A, Castleden CM. Impact of legislation on nursing home care in the United States lessons for the United Kingdom. BMJ 1999;319:1060-3.

10 Fabbrini G, Barbanti P, Aurilia C. Tardive dyskinesias in the elderly. Int J Geriatr Psychiatry 2001;16:S19-23

11 Jeste DV, Lacro JP, Bailey A, Rockwell E, Harris MJ, Caligiuri MP. Lower incidence of tardive dyskinesia with risperidone compared with haloperidol in older patients. J Am Geriatr Soc 1999;47:716-9.

12 Wirshing WC. Movement disorders associated with neuroleptic treatment. J Clin Psychiaty 2001;62:15-8.

13 Buse JB. Metabolic side effects of antipsychotics: focus on hyperglycemia and diabetes. J Clin Psychiatry 2002;63:37-41.

14 Bronskill SE, Anderson GM, Sykora K, Wodchis WP, Gill S, Shulman KI, et al. Neuroleptic drug therapy in older adults newly admitted to nursing homes: incidence, dose and specialist contact. J Am Geriatr Soc 2004 (in press).

15 Compendium of Pharmaceuticals and Specialties. Ottawa: Canadian Pharmacists Association, 2003:1505.

16 British Medical Association, Royal Pharmaceutical Society of Great Britain. British national formulary. London: BMA, RPS, 2004:179-183. (No 47.)

17 Physicians desk reference. 58th ed. Montvale, NJ: Thomson, 2004.

18 Bezchlibnyk-Butler KZ, Jeffries JJ. Clinical handbook of psychotropic drugs. 12th ed. Toronto: Hogrefe \& Huber, 2002.

19 Jadad AR, Moore A, Carroll D, Jenkinson C, Reynolds DJ, Gavaghan DJ, et al. Assessing the quality of reports of randomized clinical trials: is blinding necessary? Control Clin Trials 1996;17:1-12.

20 Jüni P, Altman DG, Egger M. Systematic reviews in health care: assessing the quality of controlled clinical trials. BMJ 2001:323:42-6.

21 Meehan KM, Wang H, David SR, Nisivoccia JR, Jones B, Beasley CM Jr, et al. Comparison of rapidly acting intramuscular olanzapine, lorazepam, and placebo: a double blind, randomized study in acutely agitated patients with dementia. Neuropsychopharmacology 2002;26:494-504.

22 Brodaty H, Ames D, Snowden J, Woodward M, Kirwan J, Clarnette R, et al. A randomized placebo controlled trial of risperidone for the treatment of aggression, agitation, and psychosis in dementia. J Clin Psychiatry 2003;64:134-43.
23 Chan W, Lam LC, Choy CN, Leung VP, Li S, Chiu HF. A double-blind randomized comparison of risperidone and haloperidol in the treatment of behavioural and psychological symptoms in Chinese dementia patients. Int J Geriatr Psychiatry 2001;16:1156-62.

24 De Deyn PP, Rabheru K, Rasmussen A, Bocksberger JP, Dautzenberg PLJ, Eriksson S, et al. A randomized trial of risperidone, placebo, and haloperidol for behavioral symptoms of dementia. Neurology 1999;53:946-55.

25 Katz I, Jeste DV, Mintzer JE, Clyde C, Napolitano J, Brecher M, et al. Comparison of risperidone and placebo for psychosis and behavioural disturbances associated with dementia: a randomized, double blind trial. J Clin Psychiatry 1999;60:107-15.

26 Street JS, Clark WS, Gannon KS, Cummings JL, Bymaster FP, Tamura RN, et al. Olanzapine treatment of psychotic and behavioral symptoms in patients with Alzheimer disease in nursing care facilities: a double-blind, randomized, placebo-controlled trial. The HGEU study group. Arch Gen Psychiatry 2000;57:968-76.

27 Folstein MF, Folstein S, McHugh PR. Mini-mental state: a practical method for grading the cognitive state of patients for the clinician. J Psychiatr Res 1975;12:189-98.

28 Reisberg B, Borenstein J, Salob SP, Ferris SH, Franssen E, Georgotas A. Behavioral symptoms in Alzheimer's disease: phenomenology and treatment. J Clin Psychiatry 1987;48:9-15.

29 Koss E, Weiner M, Ernesto C, Cohen-Mansfield J, Ferris SH, Grundman M, et al. Assessing patterns of agitation in Alzheimer's disease patients with the CohenMansfield agitation inventory. Alzheimer Dis Assoc Disord 1997;11:S45-50.

30 Cummings JL, Mega M, Gray K, Rosenberg-Thompson S, Carusi DA, Gornbein J. The neuropsychiatric inventory: comprehensive assessment of psychopathology in dementia. Neurology 1994;44, 2308-14.

31 Overall JE, Gorham DR. The brief psychiatric rating scale. Psychol Rep 1962;10:799-812.

32 Guy W. Clinical Global Impressions (CGI). In: ECDEU assessment manual for psychopharmacology. Bethesda, MD: NIMH Psychopharmacology Research Branch, 1976

33 Schneider LS, Olin JT, Doody RS, Clark CM, Morris JC, Reisberg B, et al. Validity and reliability of the Alzheimer's disease cooperative study-clinical global impression of change. Alzheimer Dis Assoc Disord 1997;11:S22-32.

34 Chouinard D, Ross-Canard A, Annable L, Jones BD. The extrapyramidal symptom rating scale. Can J Neurol Sci 1980;7:233.

35 Simpson GM, Angus JWS. A rating scale for extrapyramidal side effects. Acta Psychiatr Scand 1970;212:11-9.

36 Pwee KH, Shukla VK, Herrmann N, Skidmore B. Novel antipsychotics for agitation in dementia: a systematic review. Ottawa: Canadian Coordinating Office for Health Technology Assessment, 2003. (Technology report No 36.)

37 De Deyn PP, Wirshing WC. Scales to assess efficacy and safety of pharmacologic agents in the treatment of behavioral and psychological symptoms of dementia.J Clin Psychiatry 2001;62:19-22.

38 Ballard CG, Margallo-Lana M, Fossey J, Reichelt K, Myint P, Potkins D, et al. A 1-year follow-up study of behavioral and psychological symptoms in dementia among people in care environments. J Clin Psychiatry 2001;62:631-6.

39 Street JS, Clark WS, Kadam DL, Mitan SJ, Juliar BE, Feldman PD, et al. Long-term efficacy of olanzapine in the control of psychotic and behavioral symptoms in nursing home patients with Alzheimer's dementia. Int J Geriatr Psychiatry 2001;16:S62-70.

40 Davidson M. Long-term safety of risperidone. J Clin Psychiatry 2003;62:26-8.

41 Lindenmeyer JP, Czobor P, Volavka J. Changes in glucose and cholesterol levels in patients with schizophrenia treated with typical or atypical antipsychotics. Am J Psychiatry 2003;160:290-6.

42 Health Canada. www.hc-sc.gc.ca/hpfb-dgpsa/tpd-dpt/risperdall e.html (accessed 10 Feb 2004).

43 Food and Drug Administration. 2003 safety alert-Risperdal (risperidone) www.fda.gov/medwatch/SAFETY/2003/risperdal.htm (accessed 15 Mar 2004).

44 Professor Gordon Duff, chairman-Committee on Safety of Medicines. Atypical antipsychotics drugs and stroke. http://medicines.mhra.gov.uk/ (accessed 15 Mar 2004).

45 Schneider LS, Tariot PN, Lyketsos CG, Dagerman KS, Davis KL, Davis S. Nationa Institute of Mental Health clinical antipsychotic trials of intervention effectiveness (CATIE): Alzheimer's disease trial methodology. Am J Geriatr Psychiatry 2001;9:346-60.

(Accepted 29 April 2004)

doi $10.1136 / \mathrm{bmj} .38125 .465579 .55$

Rotman Research Institute, Baycrest Centre for Geriatric Care, 3560 Bathurst Street, Toronto, ON, Canada M6A 2E1

Philip E Lee behavioural neurology fellow

Institute for Clinical Evaluative Sciences (ICES), 2075 Bayview Avenue, Toronto, ON, Canada M4N 3M5

Sudeep S Gill adjunct scientist and geriatrician

Susan E Bronskill scientist

Department of Medicine (Neurology), University of Toronto, 190 Elizabeth Street Toronto, ON, Canada M5G 2C4

Morris Freedman behavioural neurologist

Kunin-Lunenfeld Applied Research Unit (KLARU), Baycrest Centre for Geriatric Care

Michael P Hillmer doctoral candidate

Paula A Rochon senior scientist and assistant director

Correspondence to: P Lee pelee@providencehealth.bc.ca 